\title{
Aquifer-wide estimation of longitudinal dispersivity by the combination of empirical equations, inverse solution, and aquifer zoning methods
}

\author{
Mohammad Mahdi Ansarifar ${ }^{1}$, Meysam Salarijazi $^{1}$, Khalil Ghorbani ${ }^{1}$, and Abdol-Reza \\ Kaboli $^{1}$ \\ ${ }^{1}$ Gorgan University of Agricultural Sciences and Natural Resources
}

July 28, 2021

\begin{abstract}
Longitudinal dispersivity is a key parameter for numerical simulation of groundwater quality and this parameter is highly variable in nature. The use of empirical equations and the inverse solution are two main methods of estimating longitudinal dispersivity. In this study, the estimation of values and aquifer-wide spatial distribution of longitudinal dispersivity parameter using a combined approach i.e. a combination of empirical equation method (Pickens and Grisak, Arya, Neuman, and Xu \& Eckstein equations), the inverse solution method (using the MT3DMS model with non-automatic calibration) and the aquifer zoning technique is investigated. The combined approach applied to Bandar-e-Gaz aquifer in northern Iran, and Willmott's index of agreement was used to assess the precision of simulation of total dissolved solids in this aquifer. The values of this criterion were 0.9985 to 0.9999 and 0.9756 to 0.9992 in calibration and validation periods that show the developed combined approach resulted in obtaining high precision for both calibration and validation periods and the simulation show remarkable consistency. Also, the one-way sensitivity analysis indicates that the longitudinal dispersivity is more sensitive than the effective porosity in this simulation. The investigation of the spatial distribution of the estimated longitudinal dispersivity by the combined approach indicates that the value of the parameter has a decreasing trend from the south to the north (50 to $8 \mathrm{~m})$ in the aquifer environment which is consistent with the changes in the characteristics of porous media in this study area, and therefore it concludes that the combined approach provides a reliable and appropriate estimation of the spatial distribution of longitudinal dispersivity.
\end{abstract}

\section{Hosted file}

\&\& Manuscipt With Name Revised .docx available at https://authorea.com/users/428031/ articles/532047-aquifer-wide-estimation-of-longitudinal-dispersivity-by-the-combinationof-empirical-equations-inverse-solution-and-aquifer-zoning-methods 

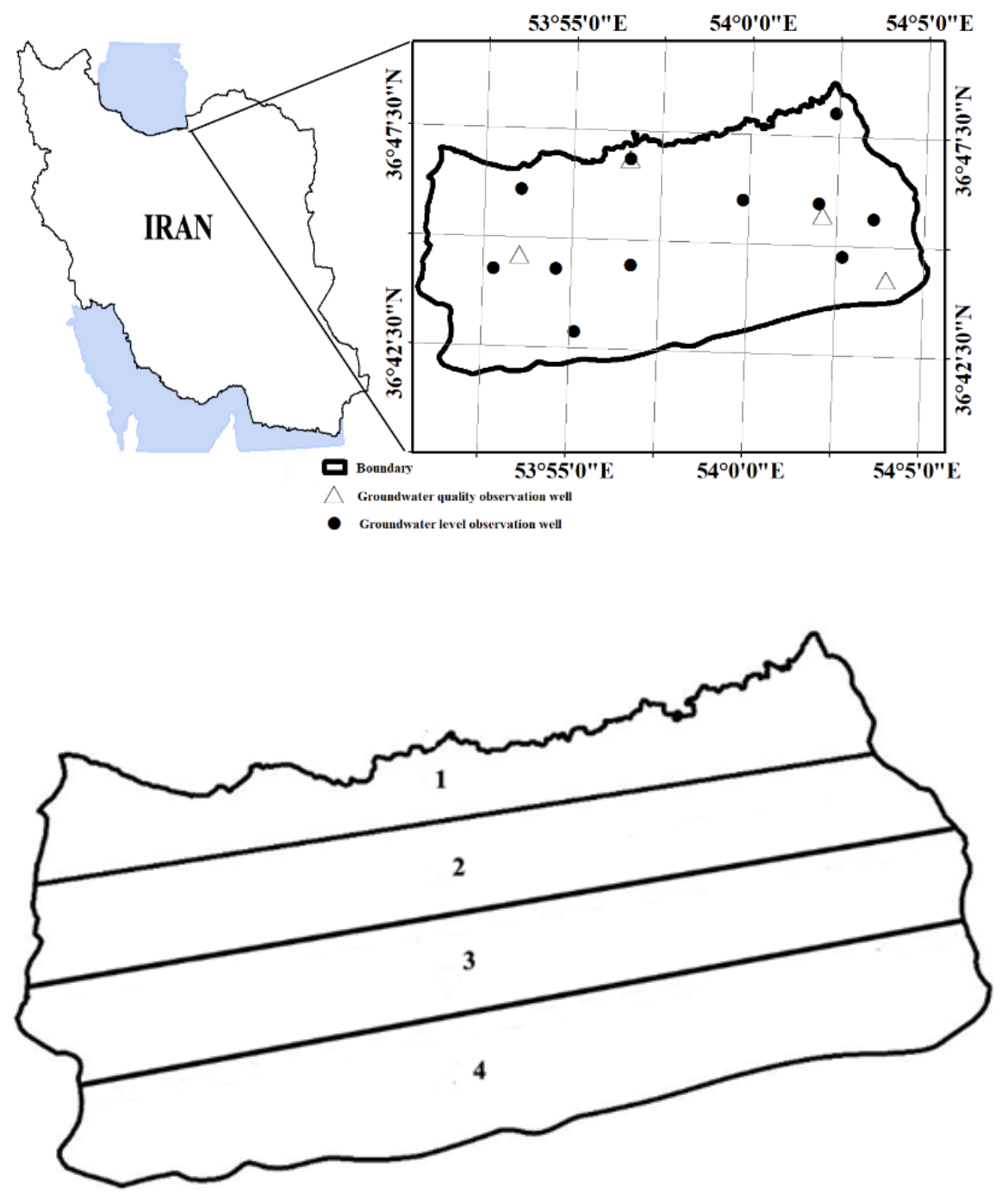

2 


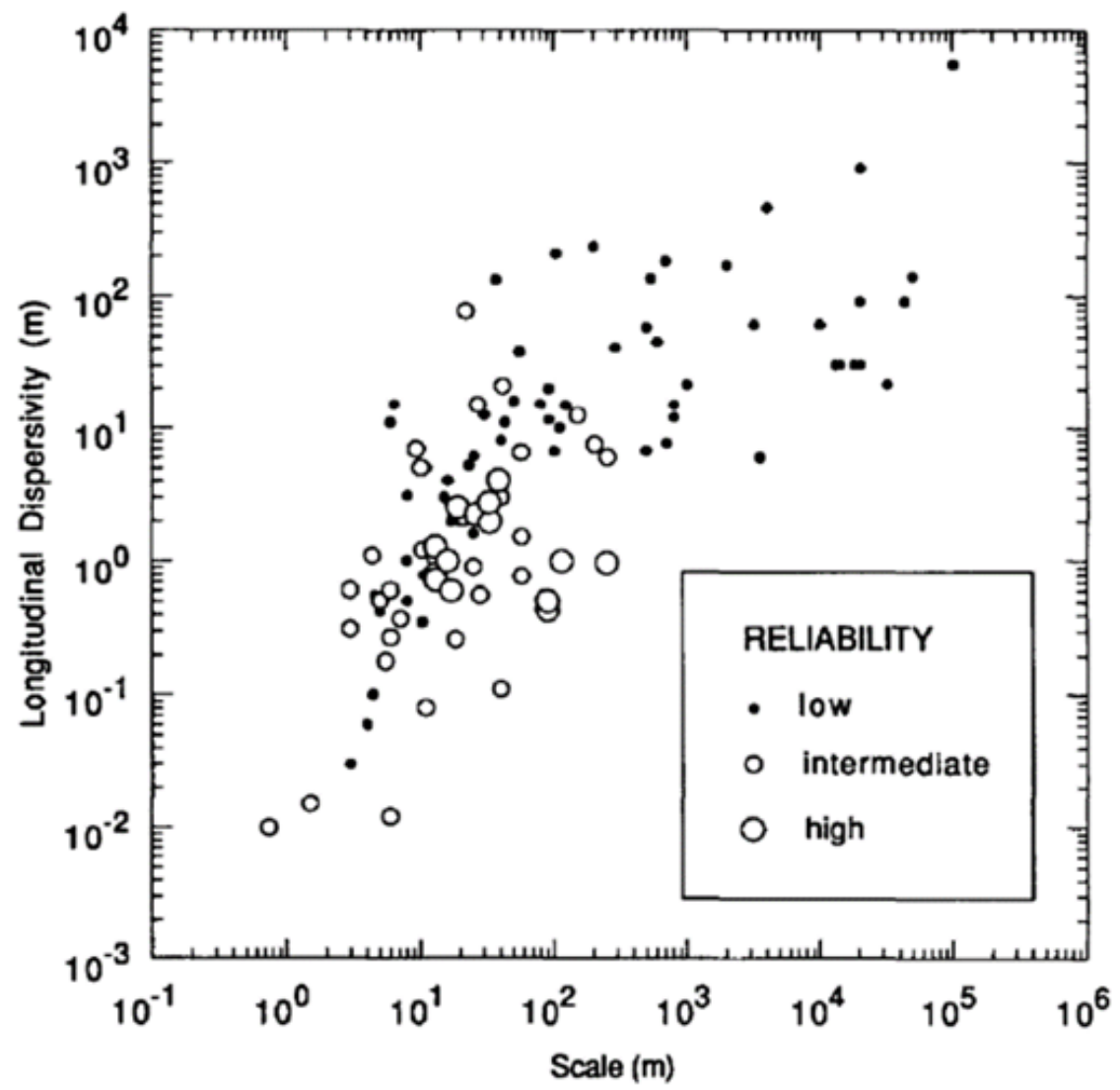


Data collection and build the conceptual and 3D grid model

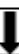

Estimation of the logical values and range for quantitative model inputs considering

field data interoretation and consultation with hvdrogeological experts

\section{1}

Inverse solution of quantitative model (Spatial estimation of specific yield and hvdranlic conductivity)

I

- Is the model precision criterion suitable?

NO

- Is the spatial distribution of the estimated parameters consistent with the characteristics of the aquifer?

\section{YES}

NO - Validation of the quantitative model

- Is there quantitative model consistency in the validation period? Yes

- Estimation of the logical values and range for qualitative model variables

- Aquifer-wide zoning

- Using the spatial distribution of effective porosity equal to specific yield map

- Approximation of longitudinal dispersion parameter using empirical equations

Inverse solution of qualitative model (Spatial estimation of longitudinal dispersivity)

The

\section{I}

- Is the model precision criterion suitable?

- Is the spatial distribution of the longitudinal dispersivity consistent with the

characteristics of the anuifer? YES $]$

$\mathrm{NO}$ Validation of the qualitative model

Is there qualitative model consistency in the validation period?

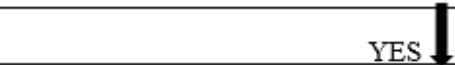

Sensitivity Analysis

0.9999

0.9998

0.9997

0.9996

0.9995

0.9994

0.9993

0.9992

0.9991

0.999 

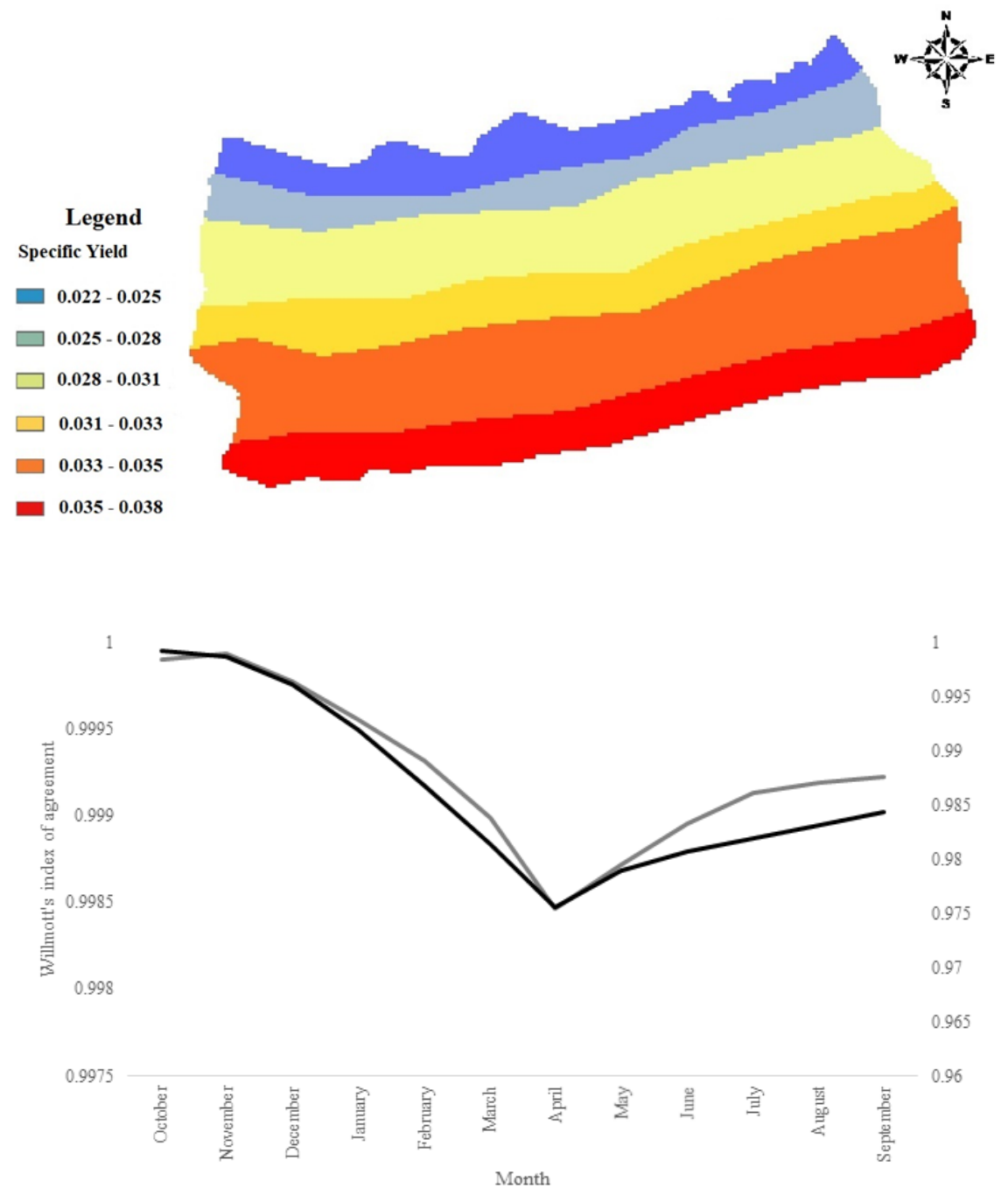

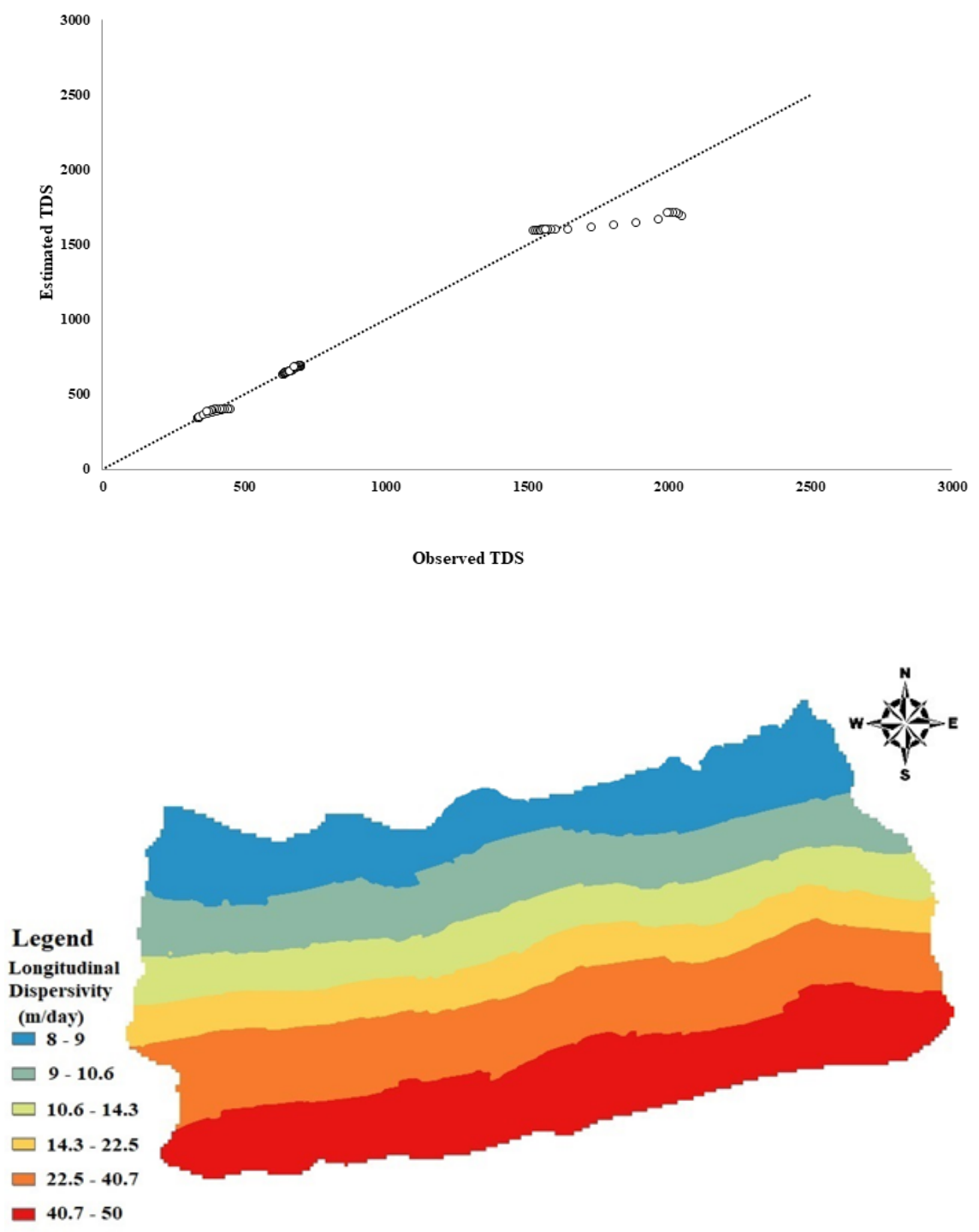


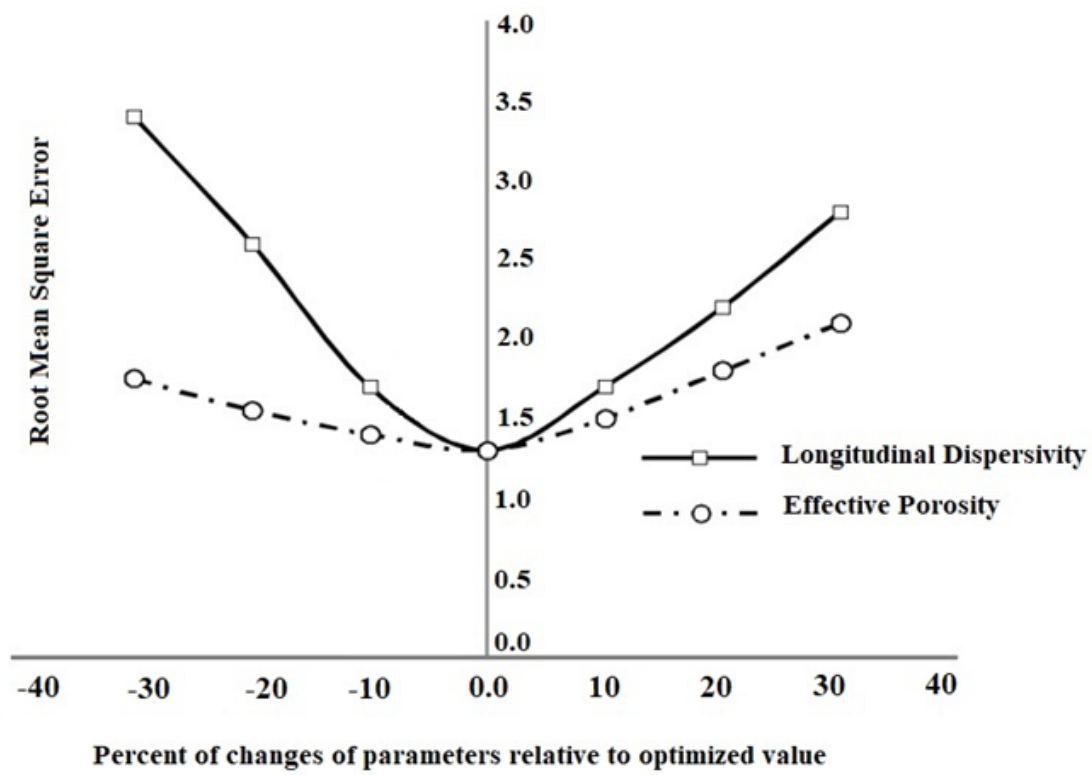

